\title{
Categorical Variables without Categorical Thinking? A Relational Reading of the Sri Lankan Demographic and Health Survey
}

\begin{abstract}
Connell's theory of gender relations is among the most influential and comprehensive frameworks for analyzing gender. Its influence across methodological approaches has been uneven, though, and Connell herself has suggested that relational theory is incompatible with statistical analyses, which, by relying on categorical dummy variables to indicate the sex or gender respondents, essentialize and fundamentally misrepresent gender. We argue that categorical variables do not require "categorical thinking." We outline three necessary steps for linking statistical analyses and relational theory: contextualizing statistical rates and means; highlighting within-group variation and the process through which it is produced, and contextualizing the data collection and research process more broadly. To illustrate our approach we critically examine data from the 2006-2007 Sri Lanka Demographic and Health Survey. We show that, far from being incompatible, relational theory is often vital for understanding the meaning of statistical data, as well as for critiquing and evaluating any resulting claims. When interpreted within a relational framework, statistical data can also clarify how gender structures the lives and experiences of people of all genders.
\end{abstract}




\section{Categorical Variables without Categorical Thinking? A Relational Reading of the Sri Lankan Demographic and Health Survey}

\section{Introduction}

Since the publication of Gender and Power, thirty years ago, Raewyn Connell's theory of gender relations has become one of the most influential and comprehensive frameworks for theorizing gender. In this and subsequent work, Connell "set out to refute the popular models of gender that had led to an intellectual and political impasse: biological essentialism, sex role theory, and all categorical approaches ... where women and men were seen as blocs sitting opposite each other" $[51,2]$. As an alternative to this "categorical thinking," Connell offered a relational theory of gender, focusing as much on the practice as the structure of gender and emphasizing the dynamic and relational aspects of gender within broader global and historical contexts.

Connell transformed the theoretical landscape for gender scholars, but her impact across methodological approaches has been uneven. Emphasizing the processes through which gender is created, reshaped and contested, as well as its variation across social and historical contexts, the theory has resonated particularly with qualitative and historical researchers. Examples of quantitative scholarship that employ a relational theory of gender are few and far between. Indeed, Connell herself has suggested that relational theory is incompatible with quantitative research and has described the use of gender as an "independent variable" - a common practice in statistical studies of gender inequality - as "illogical” [16, 1678].

Though Connell dismisses the possibility of relational statistics, we see value in linking gender-based statistics (i.e., statistics pertaining to gender groups and/or gender related issues) with relational theory. We argue that categorical variables do not require "categorical thinking" 
and outline three necessary steps for linking the two: contextualizing statistical rates and means; centralizing within-group variation and the process through which it is produced and contextualizing the data collection and research process more broadly.

To illustrate our approach, we critically examine data from the 2006-2007 Sri Lanka Demographic and Health Survey (SLDHS). We describe the Report [21] based on these data including some of the gender-based statistics it presents and then offer a critical re-reading of these statistics. We show that, far from being incompatible, relational theory is often vital for understanding the meaning of statistical data, as well as for critiquing and evaluating any resulting claims. When interpreted within a relational framework, statistical data can also clarify how gender structures the lives and experiences of people of all genders.

\section{Background}

\section{Relational Theory}

Connell proposed her relational theory of gender and further refined it, within the context of a broader "relational turn" in sociological theory. In brief, relational theorists reject the notion of the atomized individual as the basic building block of social life, and instead situate relations and interactions as the basic units of society (e.g., 27; 58). "Individuals" and other actors (e.g., states, institutions, organizations) "derive their meaning, significance, and identity" from the roles they play within relations and interactions $(27,287)$.

Connell $[11 ; 13 ; 14]$ theorizes gender as a structure of relationships operating at multiple levels of society (micro, meso, macro), that are interwoven with other social institutions (e.g., economy, politics and religion), and other social hierarchies (e.g., race, sexuality, and nation) and which, through processes such as colonization and globalization, are global in their reach. 
"Structure," Connell $[11,92]$ writes, "is more than another term for 'pattern' and refers to the intractability of the social world," but the structure is neither total nor homogenous. Nor is it finished. It is, rather, characterized by unevenness, variation, and contradiction. It is in-process, constantly recreated through expectations, interactions, and policies, and as such is subject to change. Connell uses the term "gender regime" to describe the overall pattern of relationships that occur in a particular institution or context, and "gender order" to refer to the macro-level relationships among various gender regimes [11].

Connell and Pearse [17] argue that the structure of gender relations includes four dimensions: power, production, cathexis and symbolism, which are interwoven with each other, as well as other social structures, to organize the gender order, numerous social hierarchies, and society more broadly. For Connell and Pearse, power includes interpersonal violence, power exercised through institutions, bureaucracies and the state, and, importantly, the "domination of the post-colonial world by economic and military superpower" $[17,73]$. Production includes the division of labor, spanning private and public realms (in contexts where this distinction is relevant), as well as the accumulation of capital by individuals, corporations, and states. Cathexis refers to the socially structured emotional relationships, including romantic and familial relations, but also the emotions and feeling rules [34], that are built into the workplace, other social institutions, and status hierarchies. Symbolism includes socially constructed meaning systems, as reflected in language, art, culture and other aspects of social life.

In comparison to other theoretical frameworks, Connell's relational theory offers many advantages. By focusing on relationships, and the processes through which gender is created, contested, and transformed, she avoids essentializing gender statuses and naturalizing gender differences. Connell explicitly recognizes both the material and cultural dimensions of the gender 
structure, and how these two broad aspects of gender reinforce one another across multiple life domains [see also 60]. Following post-colonial theorists [e.g., 53; 65], Connell also theorizes gender as global. For centuries, colonial powers imposed gender arrangements and ideologies as one way to dominate subjects $[10 ; 50 ; 54 ; 67]$. The processes through which gender becomes embodied within individuals, and the gendered meanings through which individuals understand themselves and others, are the outcome of not only local gender relations, but global gender relations and contestations [53].

The idea that relations and interactions, not atomized individuals, form the basic units of society, poses challenges to a number of taken-for-granted concepts, phenomena, and methods within sociology [26; 27]. Relational theorists have been particularly critical of statistical methods. As Emirbayer [27, 288] writes, "variable-based analysis... detaches elements (substances with variable attributes) from their spatiotemporal contexts, analyzing them apart from their relations with other elements within fields of mutual determination and flux." Multivariate analyses that seek to "control for" intervening and confounding variables, he suggests, further "ignore the ontological embeddedness or locatedness of entities within actual situational contexts" (289). To put it simply, attempts to isolate the effects of particular "independent variables" on a specified outcome often ignore the processes through which, and contexts within which, the "independent variables" themselves are socially constructed, often in relation with one another.

Connell focuses specifically on the misrepresentation of gender within statistical analyses. She $[13,1808]$ critiques statistical representations of gender inequality, including those produced by the United Nations Development Program, for presenting "men" and "women" as stable, selfevident groups, rather than socially created and dynamic social statuses. Moreover, by focusing on the inequality between men and women, she argues, these reports often overlook the unequal 
power relationships among men and among women, which are key elements of the gender structure [12; 14]. In another example, critiquing equal opportunity statistical reports from Australia, Connell $[15,838]$ raises two additional critiques of gender-based statistics. First, she argues, the reports reflect an understanding of gender as "two fixed categories of persons - men and women - defined by biology," with "the statistical margin of difference between these two categories" indicating "the measure of any gender problem." A second limitation is that statistical reports often focus on individual-level phenomenon and outcomes (e.g., the proportion of women in the paid labor force) and ignore the ways in which institutional practices shape gender and are often also gendered themselves. ${ }^{1}$

Connell's most sustained criticism of gender-based statistics focuses on the World Health Organization's Report, Closing the Gap in a Generation. Here she [16] argues that this Report reflects "categorical thinking" - an "essentialist" approach that "takes a dichotomous classification of bodies as the complete definition of gender." Connell contrasts Closing the Gap in a Generation with two examples of qualitative work that demonstrate the processes through which "complex social structures of gender" are embodied in individual people. She goes on to conclude that, "In the light of this argument, we cannot logically treat gender as an independent variable and health status as a dependent variable. We can give full recognition to embodiment without falling back on the categorical idea that gendered health effects are just about the biological differences between bodies" [16, 1678].

While we agree that statistical surveys and reports often rely on and reinforce problematic representations of gender, we argue that Connell undercuts the potential of both relational theory

\footnotetext{
${ }^{1}$ See for example [4]
} 
and statistical research by framing them as incompatible. To illustrate our argument, we conduct an extended case study of the 2006-2007 Sri Lanka Demographic and Health Survey and the corresponding Report which summarizes and interprets the findings. Our choice of the SLDHS is motivated by three factors. First, Connell's critique of statistical research is directed primarily at health statistics. By focusing our analysis on the SLDHS, we offer a clear and direct contrast to Connell's argument. Second, while our argument certainly applies to more complex multivariate and inferential statistics, the bivariate and descriptive statistics we examine are accessible to a wide audience. Last, by situating Sri Lanka's gender regime within and against the broader gender order, we advance Connell's call for increased attention to the global south, and to global knowledge production process more broadly [18].

\section{Data and Methods}

The Demographic and Health Surveys (DHS) Program was begun in 1984 with the stated goal of "advancing global understandings of health and population trends in developing countries." It is funded by the US Agency for International Development (USAID) and provides guidance and technical assistance to over 90 countries. A key feature of DHS program is that the surveys used in each country are standardized; though there are small variations, and while the language of administration differs, the questions asked in each country are designed to elicit similar information. Moreover, the national reports are standardized in every respect, including the number and layout of chapters to the font and page layout.

\footnotetext{
${ }^{2}$ See https://dhsprogram.com/Who-We-Are/About-Us.cfm Retrieved 9-Dec-2017
} 
Since 1999-2000, the DHS has included questions designed specifically to assess evidence of women's empowerment. The survey asks women about their control in household decision making; attitudes about wife-beating; and the rights of wives to refuse sex. Though previous researchers have questioned the extent to which these measures work equally well across diverse contexts [e.g., 63], they are designed to be standard across settings (see [45] and [46] for a comprehensive discussion of these measures).

The Sri Lankan Demographic and Health Survey also receives funds from the World Bank and significant resources from the Sri Lankan government. As per the SLDHS Report, "The Sri Lanka Demographic and Health Survey was carried out by the Department of Census and Statistics (DCS) for the Health Sector Development Project (HSDP) of the Ministry of Healthcare and Nutrition in collaboration with the World Bank. Technical support for the survey was provided by Macro International Inc., USA." The objective of the survey was to "provide the most needed data to monitor and evaluate the impact of population, health, and nutrition programmes implemented by different government agencies. Additionally, the survey aimed at measuring the impact of interventions made under the HSDP in improving the quality and efficiency of health care services as a whole" $(21, \mathrm{xv})$.

The early pages of the Report provide an overview of the context in which the survey was conducted, and within which the analyses should be interpreted. It describes Sri Lanka as a "beautiful, pear-shaped island in the centre of the Indian Ocean," approximately twenty miles southeast of the Indian subcontinent [21, 1]. It notes the country's "rich cultural heritage, stretching back about 2,500 years," as well as the country's contemporary ethnic and religious composition: 74\% Sinhalese and $8 \%$ Tamil, with the former being mostly Buddhist and the latter mostly Hindu. The Report states that, "there has been a civil war in the country for the past 25 years involving a 
Tamil guerilla group. The Northern and Eastern Provinces are especially affected, but there has been violence in other parts of the country as well” [21: 1]. Despite Sri Lanka's civil war between the government and the separatist Liberation Tigers of Tamil Eelam (LTTE) having lasted 27 years and killed over 100,000 people [23; 25], these two sentences, along with one additional passing reference mid-way through the Report, constitute the only reference to the ethnic conflict in the Report (which was published a month before the war ended in May 2009).

The Report notes the survey was carried out in 19,862 households within 20 of Sri Lanka's 25 districts. Five districts in the Northern Province (Jaffna, Kilinochchi, Mannar, Vavuniya, and Mullativu) were excluded due to the "security situation" stemming from the civil war $[21,4]$. The questionnaire comprised of two sections: one focusing on household characteristics, including age, educational attainment, and marital statuses of household residents; the other designed for "evermarried women age 15-49 years" living in the sampled households. ${ }^{3}$ The questionnaire for evermarried women includes several sections that focused on sexuality and gender, including marriage and sexual activity, awareness of sexually transmitted infections (STIs) and attitudes toward wife beating. There were 15,068 women who qualified to be interviewed, of whom 14,682 were interviewed successfully [21, 8]. Over 200 trained individuals were employed to collect the data that resulted in the SLDHS Report.

\footnotetext{
${ }^{3}$ In many countries, the DHS Program uses separate surveys for women and men. Questions related to gender inequality, sexual practices, sexually transmitted infections, and domestic violence are generally included in both surveys. In the case of Sri Lanka, only the survey for women was conducted. For further information see https://dhsprogram.com/What-WeDo/Survey-Types/DHS-Questionnaires.cfm\#CP JUMP 16181 Retrieved 9-Dec-2017.
} 
Our analysis begins by examining how gender and sexuality are operationalized and analyzed in the 302-page Report. We then focus more specifically on three key issues: women's sexual autonomy, labor force participation, and power relations within the family. We situate these statistics alongside ethnographic and historical evidence, and interpret them through a relational approach.

\section{Results}

\section{Gender Categories in the SLDHS}

As mentioned previously, the SLDHS is not designed primarily to assess gender equality, but rather to track "the impact of population, health, and nutrition programmes implemented by different government agencies" [21, xv]. Regardless of the stated aims, the Report focuses heavily on gender differences, gender-related issues, and women's health and well-being. It includes sections on "fertility" (e.g., the number of children women have given birth to, the typical time between births, as well as rates of teenage pregnancy). Multiple chapters are devoted to women's knowledge and use of contraception, women's knowledge of menstrual cycles and fertility, and their preferred family size. A chapter titled "Other Proximate Determinants of Fertility" includes information about the typical age at which women have sexual intercourse and their recent sexual activity. The final chapter focuses on "Women's Empowerment and Demographic and Health Outcomes," and includes analyses of questions related to women's control over their earnings, participation in household decision-making, and attitudes about violence against women. In brief, gender is in the foreground throughout but, as discussed below, some aspects of gender emerge more clearly than others. 
Numerous scholars have critiqued international health statistics for equating issues of "gender and health" with "women's health" and for treating gender as if it were reducible to individual-level sex differences (e.g., 6; 8; 16; see also 49]. In many ways, the SLDHS Report follows this pattern. It does not differentiate between sex and gender, and nowhere indicates that gender statuses are themselves socially constructed. The structure of gender, the processes through which gender is created, performed, institutionalized, and challenged, are not explicitly acknowledged. The Report does not acknowledge gender statuses and identities beyond the binary of "men" and "women." Nor is variation in sexuality recognized, even though respondents may interpret survey questions about "sexual intercourse" to include a range of sexual behaviors.

\section{Gender Relations and the SLDHS}

Though the SLDHS operationalizes gender in a severely circumscribed way, the Report nonetheless includes data and analyses that reveal gendered power relations and resulting inequalities. Among the demographic statistics presented throughout the Report, the social organization of gender is revealed by examining the levels of women's (and to a lesser extent men's) educational attainment, economic engagement, knowledge of contraception, and health. The Report's final chapter, titled "Women's Empowerment and Demographic and Health," includes questions about women's ability to make decisions concerning health care, major household purchases, purchases for daily needs, and visits to women's family and relatives. These questions highlight gender ideology, as well as the gender dimensions of economic and familial life.

Women's empowerment is an overarching theme of the Report. Chapter 4, "Fertility Levels, Trends, and Differentials," notes that "Overall, only 6 percent of adolescent women age 
15-19 are already mothers or are pregnant with their first child" (49). Chapter 5, "Family Planning," begins by saying that "One of the most significant positive changes in the history of empowering women that occurred in the latter half of the 20th century was opening up avenues for women to choose whether and when to have children. The 'Reproductive Revolution,' which was made possible by the availability of a wide range of modern contraceptive methods, was for the advantage of not only countries, but also individuals, and more precisely women." (51). Importantly, the Report situates statistics against the backdrop of state policies designed to reduce fertility. For instance, a Family Health Bureau was created in 1968 to increase awareness of and access to contraception, including voluntary sterilization. Subsequently, the island's Total Fertility Rate declined to 1.9 in 1998 from 3.7 in 1981 (43), which exceeded the government's goal of reducing fertility to 2.1 - the rate generally understood to generate a stable population - by 2000 , and registered Sri Lanka as the only state in South Asia that met its population target at the time $[21,57]$.

The Report also shows that fertility rates vary significantly for different subgroups: It is highest in the eastern districts (e.g., Ampara and Batticaloa) and lower in western districts (e.g., Colombo). Women in urban residences have lower birth rates than women in rural areas, who in turn have lower birth rates than Tamil women living on tea estates [45]. ${ }^{4}$

The Report emphasizes that gender arrangements and gender inequality differ significantly across the country's geographic-economic regions. For example, women in the estate sector are more likely to be economically active, compared to women in rural and urban areas; they are also

\footnotetext{
${ }^{4}$ Estate Tamils descend from South Indian indentured laborers who migrated to the island starting in the 1830s [7].
} 
more likely to have low levels of education, a higher number of children, and lower levels of wealth. Among SLDHS respondents, 50\% of women in urban areas, and $48.1 \%$ of women in rural areas, reported that wives were in charge of their earnings. In the estate sector, this figure was only $28.8 \%$. Moreover, while approximately $5 \%$ of women in urban and rural areas reported that husbands were primarily in charge of wives' cash earnings, in the estate sector, this figure was nearly five times as high (23.4\%). These differences in women's financial autonomy correlate with women's autonomy in healthcare decisions where, approximately $79 \%$ of women in rural and urban areas report making decisions about their own healthcare, compared to approximately $50 \%$ of women in the estate sector.

Besides questions concerning women's autonomy, the SLDHS included questions about gender-related beliefs, including "wife beating." Reasoning that women who tolerated husbands beating them suffer from low status, the Report asked respondents whether they believed wife beating was justified under five circumstances: "if she burns the food, argues with him, goes out without telling him, neglects the children, and refuses sexual relations with him" [21,194]. Nearly half of women respondents (46\%) indicated that wife beating was unjustified in all cases, but a third indicated that wife beating was justified in three or more circumstances. While women living in estates have lower levels of autonomy with respect to healthcare and financial decisions, beliefs about wife beating follow a different pattern. Here it is women in the rural sectors who are most likely to believe wife beating is justified: $54.5 \%$ in rural areas agreed that at least one circumstance justified wife beating, compared to $47.8 \%$ in the estate sector and $46.8 \%$ in urban areas.

The Report presents comparisons of means or rates for several outcomes (e.g., educational attainment for men and women; vaccination rates for male and female infants) and links these issues to power and gender inequality. Comparisons of means are not, however, the only method 
employed to assess gender. As described above, the Report analyzes patterns of women's economic participation, examining gender alongside education and region. Questions about women's financial autonomy and sexual decision-making, as well as knowledge about sexual health and attitudes towards gender and familial relationships, provide a window into the cultural dimensions of gender in contemporary Sri Lanka, and again, the variation that exists across social groups, age-groups, and regions. Some portions of the Report (e.g., those discussing fertility rates; rates of antenatal care) also draw attention to changes in gender relations over time.

As explained above, Connell $[11 ; 13 ; 14 ; 15 ; 16]$ argues that statistical analyses of gender suffer from numerous limitations and are incompatible with relational theories of gender. She instead calls for historically-grounded, global analyses that centralize dynamic and multidimensional relationships that construct gendered patterns in contextually specific ways. While Connell presents this approach as an alternative to statistical analyses of gender, we argue for an integrated approach. Following work in anthropological demography and mixed methods demographic research [54] we draw from ethnographic and historical studies of Sri Lanka to demonstrate what might be gained from a critical and contextualized rereading of the SLDHS Report and other demographic surveys.

\section{Contextualizing the SLDHS}

As previously noted, the SLDHS Report begins by describing the island as a beautiful pear-shaped country with 2,500 years of recorded history. It thereafter refers to the 1980 s, without noting that it was colonized for nearly 450 years by the Portuguese, Dutch, and British; was the first country in Asia to be granted universal suffrage in 1931; achieved independence in 1948; and instituted discriminatory practices against especially the Tamil minority that led to the nearly three decades 
long civil war. Space limits the extent of history that can be documented here, a challenge those who authored the SLDH Report also faced. But it is imperative to recognize that the Report is grounded within a history privileging the majority Sinhalese community (though this is not explicitly noted).

Sinhalese Buddhist cultural history is rooted in a text called the Maha Vamsa (Great Chronicle), which claims that Lord Buddha, while on his death bed, designated Sri Lanka as the place for his teachings to flourish. Buddha is also said to have asked the gods to protect Vijaya, an exiled prince from northeast India who, at that moment, landed in Sri Lanka. Vijaya, having overcome native tribes with the help of an indigenous princess, established the first Sinhala kingdom, and when one of his successors embraced and supported Buddhism, the religion thrived as predicted.

The Maha Vamsa makes it possible for Vijaya's supposed descendants to think of Sri Lanka as the island of the Sinhalese who were chosen to protect, nurture, and propagate Buddhism. This is a particularly Buddhist and Sinhala perspective of history that, in fact, invaded the Sinhala psyche with the aid of the British colonial knowledge-producing enterprise $[40 ; 20] .{ }^{5}$ British scholars and civil administrators produced knowledge about local cultures and communities to promote colonial governance and its "civilizing mission." Sinhalese Buddhist nationalist leaders opportunistically appropriated this knowledge beginning in the early $20^{\text {th }}$ century, and the resultant dominant political and cultural narrative marginalized minorities, leading to the civil war [23].

\footnotetext{
${ }^{5}$ The Portuguese and Dutch only colonized parts of Sri Lanka. The British administratively unified the island in 1815 and were mainly responsible for transforming the economy, culture and politics.
} 
Against this backdrop, we might read the SLDH Report itself as a continuation of this perspective, and indeed a product of both the symbolic and power dimensions of the gender order as described by Connell.

\section{Colonization and the Transformation of the Sri Lankan Gender Regime}

Historical evidence documents that, prior to colonial rule, women, including married women, enjoyed flexibility in sexual norms. One British scholar, writing in the $19^{\text {th }}$ century, noted "the infringement of chastity scarcely subjects a woman either married or unmarried to the slightest reproach" [57, 177]. Another commented, "From the lowest to the highest castes in all parts of Ceylon, the want of conjugal fidelity (and chastity in the unmarried) is most terrible," and further notes that a husband could lend his wife to a man of higher caste to fulfill an obligation $[64,165]$.

Within the context of colonialism, these characterizations of Sinhala marriage and women's chastity were used to justify and sustain British domination. And, in response to this reproach of familial ideals, and in particular women's sexuality, Western-educated local male elites responded by attempting to align marriage practices with dominant British ideals. They, therefore, aided the British government in implementing homogeneous laws for marriage, divorce, and inheritance. In 1859 the British government issued Ordinance No.13, organizing marriage customs into one cohesive set of rules based on the British understanding of marriage. The ordinance declared monogamous union was the only legal form of marital relationship and no marriage could be dissolved without court proceedings. To obtain a divorce, strict criteria had to be followed to establish grounds: adultery, adultery with cruelty to the wife, or desertion for five years. These changes reduced women's power within marriages, effectively preventing women 
from leaving their husbands and returning to their parental village [61]. Importantly, these regulations, and the ideologies reflected within them, continue to shape gender relations today.

The transformation and regulation of gender and sexual relationships were strengthened by the colonial system of education. Christian missionary women sought to mold native women into good companions for men $[33,33]$. While missionaries sought to teach native girls virtues of femininity and domesticity, nationalists saw this professionalization of domesticity as crucial to transforming the Sinhala Buddhist woman into a symbol of national greatness [20]. Missionaries sought to inculcate new manners and habits in young women that were distinct from men and thereby initiated gendered spheres, and at the micro-level, transformed gendered selves. The projected ideal was "to be civilized" and "restrained in all manner and thought." To be otherwise was to be "uncivilized," "uneducated," "unsophisticated" and "uncultured." The humiliation the nationalist elite felt at British perceptions of local life led them to construct a notion of the "new woman" - one who would be educated and accomplished at the same time as she upheld all the spiritual qualities for which Asian women were thought to be renowned. In the late nineteenth and early twentieth centuries, their efforts incorporated and transformed syncretic and often locally specific cultural ideologies into what became mainstream Sinhala Buddhist ideology [20].

Within this relatively unified religious, cultural formation, the sexual division of labor was constructed by an admixture of local patriarchal values and British Victorian ideals. The nascent middle class, which was not only Buddhist but also Hindu and Christian, started to project an ideal of women as "passive, subordinate and confined to nurturing and servicing roles within and outside the home" $[38,8]$. Victorian ideals also contributed to new expectations that middle class women should be protected within the fold of the kin group "exhibiting the same aura of passive "feminine" serenity as women of their class in Britain at the time" $[61,52]$. This unified 
ideology quickly began to spread to other sections of society and eventually affected women of all classes.

Among the nationalist elite who were responsible for these changes, Anagarika Dharmapala's contribution was singularly important in recasting woman as protector and reproducer of spirituality/ tradition/ culture in the early $20^{\text {th }}$ century. Citing Buddhist Pali texts, he dictated specific duties of wives and husbands to each other, thus creating a standardized sexual division of labor, with a masculinized public sphere and feminized private sphere. This was further stabilized by the publication of a general manual of conduct and a special thirty-rule manual of conduct for women, containing instructions regarding manners and conduct of household duties. Dharmapala's ideas were published in several Sinhala language magazines and he toured the country shaming people into giving up old ways [31]. Because the new gender norms were imparted as part of the anti-colonial movement, they quickly captured the fascination of many sections of society. The dissemination was further aided by the print media - newspapers as well as literary sources such as novels and poems of the time, which promoted nationalist fervor together with new gender norms.

After independence in 1948, the new leaders adopted this unified Buddhist culture and its attendant rituals as the basis for state culture. Subsequently, it was officially disseminated through schools and the mass media. Coupled with the constant bombardment through news media, films, songs, novels and school textbooks, this further etched ideal images of the women, men and heterosexuality in the public psyche. Many movies in this early era portrayed the good woman as one who was obedient, a virgin at marriage and an efficient and religious wife/mother. Jayamanne writes that the generic Sinhala cinema contains a set of binary oppositions such as 
city/village, bad/good and westernized/traditional [37, 57]. In many of these movies the bad woman meets with some kind of punishment, such as public humiliation, illness or death.

The stories in textbooks for lower grades especially were peppered with advice about ideal behavior and the consequences of failing to meet these ideals [30, 18]. Jayaweera contends that in post-independence Sri Lanka, the "educational material and 'hidden curriculum' reinforce stereotypes and tend to circumscribe the experiences and aspirations of girls" $[38,8]$. In schools and Sunday Buddhist schools young women were given additional instructions on norms of shamefear- to be ashamed to break behavioral norms and to fear the social ostracization for doing so. The effects of this indoctrination take different forms among women of different social groups, and women of all classes differently negotiate these ideals in their everyday lives.

It is worth repeating that, like the Demographic and Health Reports of other states, the SLDHS presents recent statistics almost entirely devoid of historical and global context. The omission of the historical processes through which gender statuses, relationships, sexuality, and ideology are created and institutionalized is a significant limitation, if read as a stand-alone document, and sets the stage for interpreting contemporary gender-based statistics with an individualistic, essentialist and a-historical framework. On this point, we strongly agree with Connell. There are other ways to read this Report, however. As we show below, gender-based statistics, when combined with qualitative scholarship, can be interpreted in ways that draw attention to the relationships that shape gender, in contextually specific ways, across multiple levels of society. In the following section we provide a framework for re-reading SLDHS statistics as they relate to these historical, socio-economic and cultural contextualities.

\section{Contextualizing Rates and Means}


The SLDHS uses the term 'Reproductive Revolution' to describe the country's meeting the goal of lowering the birth rate from 3.7 to 2.1 during the latter half of the twentieth century $[21,51]$. Chapter 5 also describes high levels of knowledge and use of contraceptives among ever-married women and very low teen pregnancy rates resulting from state policies promoting reproductive health and birth control. Compared to most other South Asian countries, Sri Lanka is indeed successful in maintaining low birth rates. Very high literacy rates for both men and women (92\% and $94 \%$ respectively), and good public health education campaigns, aided the widespread knowledge and acceptance of contraceptive usage, especially among married women. Throughout the Report, the statistics are presented as evidence of women's increasing empowerment, and reduced gender inequality.

Ethnographic and historical scholarship offers a less sanguine image of Sri Lankan gender relations, and an alternative framework for interpreting the findings from the SLDHS. While this literature is vast, we focus on issues of sexuality, familial relations, and reproduction. As discussed below, ethnographic accounts raise questions about the extent to which statistics based on married women's experiences may overshadow the experiences of women who are more marginalized and vulnerable, as well as the extent to which women's knowledge of sexual health may or may not reflect sexual autonomy. To be clear, our goal is not to refute the findings of the Report, but rather to illustrate one approach for interpreting the findings from SLDHS within a relational framework, while also using the SLDHS findings to clarify the relations that structure the Sri Lankan gender regime.

Earlier we noted that the SLDHS Report is based on data for 14,692 ever-married women (that is, women who are currently married or were at one time) aged 15-49. Approximately $89.4 \%$ of Sri Lankan women aged 15-19, and 40\% of those aged 20-29 are never married [22]. 
Approximately $5 \%$ of women aged 50 and above, in contrast, are unmarried. While the authors of the Report note throughout that the data applies only to ever-married women, the presentation of these data, without supplementary information from those who have not (yet) married, may present a distorted image of Sri Lankan gender relations, due to the vastly different social conditions, expectations and experiences of unmarried women in Sri Lanka and other South Asian countries.

Author's [2008; 2016] research among Sri Lanka's global factory workers, 90\% of whom were unmarried, illustrates this idea well. Through ethnographic analyses of rural women who had migrate for work to the Katunayake Free Trade Zones (FTZs), Author [2006; forthcoming] shows that, while they are knowledgeable about reproductive choices, women living and working in the FTZs have difficulty acting on their knowledge, due to the internalized dominant cultural ideals as well as the material conditions of life in the FTZs. Living in makeshift boarding houses, away from their families, and working long hours at global assembly lines, these women workers find solace in romantic relationships with working class men who frequent the area. Moreover, because they live alone away from families, and are willing to enter into romantic relationships, the general public has already condemned them as transgressive women with loose morals. Men regularly try to take advantage of them by coercing them into sexual relationships that in most cases women did not want. Unfortunately, this contributes to unwanted pregnancies, abortions at illegal, unsanitary clinics, and occasional infanticide and suicide [Author 2006; 2010; 2016; 43; 44]. Though the experiences of unmarried women in FTZ's cannot be generalized to the larger population of unmarried women in Sri Lanka, the omission of unmarried women's experiences from the Report may reveal an overly sanguine image of women's empowerment.

More broadly, ethnographic research shows that the colonial constructions of the "good woman" infuse the symbolic and cathexis dimensions of the gender regime. Women's virginity at 
the time of marriage is still emphasized and, although the practice of communal checking has faded, men are still brought up to think that a good woman is someone who has no knowledge of sex before marriage. Songs and other literary work celebrate men initiating young, innocent (of sexual knowledge) women into sex. Moreover, although many men desire premarital sex with women, most do not want to marry girlfriends who had sex with them, resulting in unwanted pregnancies, abortions, and feelings of shame among FTZ workers.

Funded by the World Bank, and with the explicit objective of providing "data needed to monitor and evaluate the impact of population, health and nutrition programmes implemented by different government agencies" [21,4], the SLDHS Report celebrates Sri Lanka's low rates of teen pregnancy. The report emphasizes that the country enjoys high levels of sexual knowledge, empowerment, and permissiveness. This claim, however, can be interpreted differently given what is noted above on social constructions of ideal (heterosexual) womanhood and a state culture deeply entrenched in these notions of gender and sexuality.

The importance of virginity and the dangers of premarital sex continue to saturate the contemporary cultural landscape $[62 ; 52]$. Although the lingering importance given to virginity at the time of marriage was a result of Victorian influence, the ritual of checking a woman's virginity on the wedding day is touted as an ancient custom [25;26]. Thus many movies, though center on romantic love, lecture about the "evilness" of pre-marital sex and importance of virginity at marriage [Author 2016; 48]. Moreover, school textbooks, especially books for studying Buddhism as a subject, and the Sunday school curriculum continue to extoll the virtues of avoiding romantic and sexual relationships before marriage.

Although satellite television and social media now expose young people to different ways of thinking about sex and sexuality, the constructed norms that are deeply entrenched in the social 
fabric shape how such knowledge is absorbed and practiced. Except among elite Colombo youth, pre-marital sex is not prevalent due to the social constraints placed on the practice (Author 2016; forthcoming; 62). Even when premarital sex happens and pregnancy occurs, the incidents are kept secret and dealt within the family to manage the young woman's reputation. Many families abandon their villages/localities to leave behind the stigma of rumors about their teen daughters. In such circumstances, it would be surprising if the teens or their parents report the unwanted pregnancy or how they dealt with it - often via abortion (which is illegal in Sri Lanka) at roadside clinics.

To summarize, a rereading of the SLDHS Report begins with contextualizing rates and means, because without this context, the rates and means presented are subject to a range of different interpretations. One reading might emphasize the empowerment of individual women and, in more theoretical terms, might emphasize gender as a relatively stable characteristic of individuals (or, worse yet, a characteristic of women only). When read alongside the ethnographic data, and within a relational theoretical framework, however, these same statistics can be seen as reflecting the numerous intertwined processes and relationships that construct gender categories and give them meaning. Such a reading might emphasize a history of colonialism intertwined with sexual repression alongside successful public health education. This rereading also draws attention to the historical processes through which gender and sexual norms emerged, along with the institutional arrangements that continue to structure the lives the statistics encapsulate.

\section{Highlighting Variation \& Intersectionality}

In addition to presenting statistics about the status of women in general, the SLDHS Report disaggregates statistical information along dimensions of age, socio-demographic status and, 
perhaps most importantly, region. Largely due to the intertwined histories of colonialism, tea production and inter-ethnic conflict, contemporary Sri Lanka is marked by a high degree of regional ethnic segregation.

The statistics disaggregated by region, some of which we discussed earlier, reveal profound regional differences in the social organization of gender. But, as Connell [16] argues, highlighting differences, without attention to the power relations through which differences are created, maintained, and experienced, presents a severely limited - and arguably distorted — view of the wider gender regime. Indeed, the Report avoids making comparisons across ethnic groups, and instead relies on de-contextualized "regional" differences. As explained below, regional differences in Sri Lanka's social organization of gender do not materialize from thin air and cannot be understood without attention to the historic relations of oppression and subjugation of ethnic minorities, the poor, and women.

Ancestors of Estate Tamils, who lived and worked in Sri Lanka's tea plantations, first migrated to Ceylon (as Sri Lanka was known under British rule), in the 1830s through a system very similar to indentured labor. Due to rural poverty, Tamil people in and around Madras city of South India chose to participate in a labor-recruiting system that circuitously bound them to the recruiting agent (kangani) and the plantations [55]. Although many promises were made at the time of recruitment, plantation owners, $90 \%$ of whom were British, broke them, and workers subsisted with very low wages, as well as poor living and working conditions.

By the time of the 1911 Census, these workers and their families were labeled as Indian Tamils, despite the fact that by this time more than $40 \%$ of the Estate Tamil population was born and raised in Ceylon. This label put them in a precarious position where they were considered belonging to a country that many had never visited. Moreover, the predominant indigenous Tamil 
community located in the northern district of Jaffna reviled their counterparts in the estate sector due to their low class and caste positions [7]. In 1948 the first government of independent Sri Lanka disenfranchised the Estate Tamils, leaving most of them stateless. Then, in 1964, a bi-lateral agreement between India and Sri Lanka saw 525,000 Estate Tamils condemned for repatriation to India. This led to tragic stories of families being broken apart and repatriated Tamils not being accepted in India. In 1984 repatriation officially ended and all Estate Tamils became Sri Lankan citizens by $2003[41 ; 42]$.

Meanwhile, successive governments, before and after independence, neglected the plight of the Estate Tamil population and delegated the provision of housing, education, and health facilities to the tea estate management. Profit-maximizing concerns led to estates not providing good housing and health facilities, while the reluctance to lose the ready, residential, low-wage tolerating group of people led to the appallingly bad schools in the estate areas. More than the lack of good schools, the need for all family hands at work to make ends meet resulted in successive generations of Estate Tamil youth (regardless of gender) doing the same low-paid jobs as their parents. Girls and boys would terminate secondary education at grades 5-7 either to join plantation work or to move to urban areas as domestic servants [7;39].

The historical and cultural overview provided here, while necessarily incomplete, provides a vital framework for interpreting the regional and ethnic variation documented in the SLDHS Report. The Report highlights profound regional differences across a number of social and healthrelated characteristics, including women's educational attainment (12), nutritional intake (157), knowledge of HIV (176), use and ownership of mosquito nets $(163,168)$, to name just a few. It also highlights the production and power dimensions of Sri Lanka's gender regime. As noted above, The Report (79) shows that while $34 \%$ of women in urban areas were engaged in economic 
activities, this figure more than doubles for women living in estates $(71 \%$ of whom were engaged in economic activities). While in other contexts, and especially when interpreted within a neoliberal framework, women's labor force participation is read as a sign of empowerment, the ethnographic and historical scholarship presented here frames women's workforce participation in the estate sector as stemming from abject poverty and a lack of viable alternatives. ${ }^{6}$ Autonomy in financial decisions, while an important indicator of gender relations in some contexts, may, in the context of estate households, be a poor measure of gender equality. ${ }^{7}$ Interpreting statistical data within the context of ethnographic scholarship provides insight into the meaning of statistical rates and means, and the relations of power through which they emerge; attention to variation across social and regional groups reveals the unevenness and contextual specificity of gender regimes, and shows its interconnections with other institutions and hierarchies.

Effects of decades of ethnic oppression, segregation and exclusion from social goods and services have shaped contemporary forms of gendered economic exclusion and social violence. Thus, without taking into consideration the complex histories of marginalization and political invisibility, the statistics alone fail to present a clear picture of economic and social empowerment or lack thereof.

\footnotetext{
${ }^{6}$ See also Riley [59,122-124].

${ }^{7}$ Riley [59, 115-116] argues that financial autonomy is a poor indicator of women's empowerment in Southeast Asia more generally. In comparison to Western societies, those in Southeast Asia place a higher value on social interdependence, and with this interdependence comes increased social status. See also [45] and [63].
} 


\section{Discussion}

As explained above, Connell and other relational theorists argues that statistical reports like the Demographic and Health Survey often reflect "categorical thinking" - essentialist and biologically-rooted notions of gender, in which gender is conceptualized as a stable and selfevident, and biologically-rooted characteristic of individuals. Connell contrasts this approach with her relational theory of gender, in which gender is understood as a socially constructed and dynamic phenomenon, cutting across multiple levels of society and intersecting with other global hierarchies and social institutions. A relational theory of gender draws attention to the relationships - not only across genders, but within genders; not only within a particular society or institution but among multiple communities - and indeed among nations and international organizations — within which gender is actively constructed and contested.

While Connell equates gender-based statistics with "categorical thinking," and suggests statistics are incompatible with a relational framework, we believe this is a mistake. Here we have offered a critical rereading of the SLDHS Report as an example of one way to bridge statistical and relational scholarship. Our analyses highlight three key take-away points for researchers who might wish to do the same. First, survey research and the statistical data they generate need not be interpreted as biologically-grounded or essentialist. Second, when reading statistical analyses, attention to variation is equally important as differences in means. And third, statistical reports, like any other cultural representation or narrative, must be understood within the historical, institutional, and relational contexts within which they were produced. We elaborate on each below.

It is entirely possible to conceptualize categories such as gender, as socially created social 
statuses, and to use these categories to highlight the ways in which these statuses, and the hierarchies built upon them, structure the lives of individuals and groups in a particular context. Whether in social movements [65] or in quantitative analyses [9; 49], the provisional and strategic use of categories does not require an essentialist understanding of these categories, nor does it preclude attention to gender at an institutional level. Most certainly it does not require biologicalrooting.

As we discussed above, ethnographic and historical scholarship show how colonialism transforms ideologies of gender and sexuality, as well as familial and economic institutions; how ethnic and socio-economic divisions are both heightened and manipulated by colonial elites in pursuit of profit and control of resources; how majority Sinhala elite appropriated British narratives and gender ideals to subjugate women and ethnic minorities. This scholarship makes clear that the gender, ethnic, and regional categories employed in the Report are all socially created, dynamic, and produced within global relationships. We argue that the statistics based on these categories can be read as such - as an outcome of these processes, though one that is also subject to change. At the same time, they can also be read as indicators (however imperfect and dynamic) of the continued relevance of socially created gender-based categories for organizing social life.

Critiquing the prevailing gender framework, which conceptualized women and men as "blocs sitting opposite each other" [51, 2], Connell's theory of gender relations argues that diversity within genders, and more specifically power hierarchies within gender groups, were as important for understanding gender as were differences between men, women, and other gender groups. Connell $[11 ; 1315 ; 16]$ links this categorical approach with quantitative research. We agree that in too much quantitative research, diversity within particular gender groups is not sufficiently addressed. What we have shown here, however, is that within-group variation is a key 
theme of the SLDHS report. The statistics included in this Report, like many others, show gender intersecting with ethnicity, class, and age, and intertwined with economic structures and geography. Data showing how women's economic participation, fertility rates, and gender-related beliefs have changed over the past several decades illustrates changes in the broader gender order. Though not the central narrative of the Report, the statistics within it could be used to highlight the enduring disadvantage of state sector Tamils, for example, who now prefer to be called Upcountry Tamils to highlight their nativeness. Reading statistics within a relational framework requires attention to variation - not only to differences, but also to the relationships (often unequal) as well as historical and contemporary processes that create and give meaning to these differences. Multivariate statistical analyses of SLDHS data would reveal more nuanced and complex patterns of variation.

A final theme of our analysis, and of Connell's relational theory, is attention to the global power relationships that structure the gender order. Funded by USAID and the World Bank, and conducted in partnership with international and Sri Lankan actors, it is vital to understand the Report itself as the product of global power relations. While providing valuable information for the state, organizational- and individual-level actors within Sri Lanka, and indeed conducted in partnership with numerous Sri Lankan individuals, the SLDHS and the resulting Report has some elements of what Connell [18], following Hountondji [35], describes as "extroversion"- reliance on methods produced in the Global North, reflecting the values and knowledge systems of these power centers, and produced, at least in part, for an audience external to Sri Lanka. To say this is not to undercut the agency of the Sri Lankan actors involved. The Report was written by Sri Lankan researchers and the data have been used almost exclusively by scholars within Sri Lanka. The 
decision not to release the underlying data to the public domain can be read as contesting the hegemony of the global North, a demand to speak for oneself, rather than be spoken for.

Yet, neither the existence of the Report, the narrative found within it, nor the data on which it is based can be accurately understood without attention to the broader context in which it was produced [32]. While we believe the statistics the Report provides are valuable and we emphasize that there is significant "buy in" from the state of Sri Lanka and individual actors, external institutions such as USAID, the DHS program, and the World Bank exert power over which social groups, which axes of inequality, and which social issues are represented in its pages. So, for example, the SLDHS draws attention to the experiences of ever-married women, but not unmarried women, sexual minorities, or transgender people. It highlights regional differences, but in many ways obscures ethnic inequalities. In linking global institutions and power inequalities to the production of gender statuses and difference, Connell's theory provides the theoretical tools necessary for understanding the Report itself. With this perspective, we can see the Report as a part of the larger global gender discourse that frames gender in the context of population control, “development," and individual women's empowerment. It is a product of the gender order, and, at least on the surface, can strengthen this system. But an alternative reading is possible.

\section{Conclusion}

We have argued that gender-based statistics can interpreted from within a relational framework and can draw attention to the historical and global processes, structures, as well as the contextually specific gender orders that are reflected in statistical data. We emphasize again that the pre-colonial notions of gender, the colonial cultural transformations, specific tactics of the anti-colonial movement, and the particular post-colonial state policies on development, education, health, media 
and wealth distribution are all crucial aspects of any relational analysis of gender in this context. All are missing from the SLDH survey narrative, giving credence to Connell's critique. Moreover, the Report focuses overwhelmingly on women's empowerment and women's health, and in doing obfuscates the ways in which men and other gender groups are affected by gender relations [16; 6]. Despite these limitations, statistical analyses are not at all incompatible with a relational framework. In fact, it is more likely that the opposite is true: A relational framework is vital for understanding the meaning of statistical data, as well as for critiquing and evaluating resulting claims. 


\section{REFERENCES}

1. Abeysekera, S. (1989). Women in Sri Lankan cinema. Framework. 37:49-58.

2. (1998). Women, sexuality, the city and the village. Pravada. 5(4\&5):39-42.

3. (1998a). Fifty years of cinema in Sri Lanka: Looking back, moving forward.

Options. 13(1): 2-6.

4. Acker, J. (1990). Hierarchies, jobs, bodies: A theory of gendered organizations. Gender \& society. 4(2): 139-158.

5. Amunugama, S. (1991). A Sinhala Buddhist "Babu": Anagarika Dharmapala (1864-1933) and the Bengal connection. Social science information. 30(3):555-591.

6. Annandale, Ellen, and Kate Hunt, eds. (2000). Gender inequalities in health. Buckingham: Open University Press.

7. Bass, Daniel. (2013). Everyday ethnicity in Sri Lanka: Up-country Tamil identity politics. London: Routledge.

8. Bates, L.M., Hankivsky, O., and Springer, K. (2009). Gender and health inequities: a comment on the final report of the WHO commission on the social determinants of health. Social science \& medicine. 69(7): 1002-1004.

9. Budig, M. J., \& England, P. (2001). The wage penalty for motherhood. American sociological review, 204-225.

10. Chatterjee, P. (1993). The nation and its fragments: Colonial and post colonial histories. Princeton: Princeton University Press.

11. Connell, R. (1987). Gender and Power. Cambridge: Polity Press.

12. (1992). A very straight gay: Masculinity, homosexual experience, and the dynamics of gender. American sociological review. 57(6): 735-751. 
13. (2005a). Masculinities. Berkeley: University of California Press.

14. (2005b). Change among the gatekeepers: Men, masculinities, and gender equality in the global arena. Signs: Journal of women in culture and society 30(3): 1801-1825. 15. (2006). Glass ceilings or gendered institutions? Mapping the gender regimes of public sector worksites. Public administration review. 66(6): 837-849.

16. (2012). Gender, health and theory: conceptualizing the issue, in local and world perspective. Social science \& medicine. 74(11): 1675-1683.

17. Connell, R., \& Pearse, R. (2014). Gender: in world perspective. Cambridge. Polity.

18. Connell, R., Collyer, F., Maia, J., \& Morrell, R. (2017). Toward a global sociology of knowledge: Post-colonial realities and intellectual practices. International Sociology, 32(1), 2137.

19. De Alwis, M. (1995). Gender, politics and the 'respectable lady.' In P. Jeganathan and Q. Ismail (eds.), Unmaking the nation: The politics of identity and history in modern Sri Lanka. Colombo: Social Scientists’ Association.

20. (1997). The production and embodiment of respectability: Gendered demeanors in colonial Ceylon.” In M. Roberts (ed.), Sri Lanka collective identities revisited (pp,105-143). Colombo: Marga Institute.

21. Department of Census and Statistics (DCS) and Ministry of Healthcare and Nutrition (MOH). (2009). Sri Lanka demographic and health survey 2006-07. Colombo, Sri Lanka: DCS and $\mathrm{MOH}, 2009$.

22. Department of Census and Statistics (DCS). (2014). The Sri Lankan women: Partner in progress. Colombo, Sri Lanka: DCS. 
23. DeVotta, N. (2004). Blowback: Linguistic nationalism, institutional decay, and ethnic conflict in Sri Lanka. Stanford: Stanford University Press.

24. (2007). Sinhalese Buddhist nationalist ideology: Implications for politics and conflict resolution in Sri Lanka. Policy Studies. 40. Washington D. C.: East-West Center.

25. (2009). Liberation Tigers of Tamil Eelam and the lost quest for separatism in Sri Lanka. Asian Survey. 49 (6):1021-51.

26. Donati, P. (2014). Relational Sociology and the globalized society In F. Dépelteau, and C. Powell (eds.), Applying Relational Sociology: Relations, networks, and society Macmillan. 27. Emirbayer, Mustafa. (1997). Manifesto for a relational sociology. American Journal of Sociology, 103: 281-317.

28. Gombrich, R., and Obeyesekere, G.. (1988). Buddhism transformed. Princeton: Princeton University Press.

29. Grossholtz, J. (1984). Forging capitalist patriarchy: The economic and social transformation of feudal Sri Lanka and its impact on women. Durham: Duke University Press.

30. Gunasekera, M. (1994). The splintering of Aladdin's myth: Education, occupational mobility and the social context. Options 2:17-20.

31. Guruge, A. (1965). Anagarika Dharmapala: Return to righteousness. Colombo: Government Press.

32. Harding, S. ed. (1987). Feminism and methodology: Social science issues. Bloomington: Indiana University Press.

33. Harris, E. (1994). The gaze of the colonizer: British views on local women in 19th Century Sri Lanka. Colombo: Social Scientists’ Association. 
34. Hochschild, Arlie Russell. (1983) The Managed Heart: Commercialization of Human Feeling. Berkeley, Cal.: University of California Press.

35. Hountondji, P. J. (Ed.). (1997). Endogenous knowledge: Research trails. African Books Collective.

36. Hyndman, J. (2014). 'No more tears sister': Feminist politics in Sri Lanka." In Alternative development: Unravelling marginalization, voicing change, 155-167. Farnham, UK: Ashgate. 37. Jayamanne, L. (1992). Hunger for images, myths of femininity in Sri Lankan cinema 19471989. South Asia bulletin. xxi(1):57-75.

38. Jayaweera, S. (1990). Women and Development: A Reappraisal of the Sri Lanka Experience. In Center for Women's Research (ed.), The hidden face of development: women, work and equality in Sri Lanka. Colombo: CENWOR.

39. Jegathesan, M. (2019). Tea and Solidarity: Tamil Women and Work in Postwar Sri Lanka. Seattle: University of Washington Press.

40. Jeganathan, P. and Q. Ismail. (1995). Unmaking the nation: The politics of identity and history in modern Sri Lanka. Colombo: Social Scientists' Association.

41. Jegathesan, M. (2010). Bargaining in a labour regime. Himal South Asian. February: 38-41. 42. . (2013). Bargaining in a labor regime: Plantation life and the politics of development in Sri Lanka. (Doctoral Dissertation) Columbia University: New York City. 43. Jordal, M., Wijewardena, K., Öhman, A., Essén, B., Olsson, P. (2015). Disrespectful men, disrespectable women': Men's perceptions on heterosexual relationships and premarital sex in a Sri Lankan Free Trade Zone - A qualitative interview study. BMC International Health and $\underline{\text { Human Rights, } 15 .}$ 
44. Jordal, M., Wijewardena, K., Öhman, A., Essén, B., Olsson, P. (2014). Negotiating Respectability: Migrant Women Workers' Perceptions on Relationships and Sexuality in Free Trade Zones in Sri Lanka. Health Care for Women International, 35(6): 658-676

45. Kishor, S. (2005). A focus on gender: collected papers on gender using DHS data.

46. Kishor, S., \& Subaiya, L. (2008). Understanding women's empowerment: a comparative analysis of Demographic and Health Surveys (DHS) data.

47. Knighton, W. (1854). Forest life in Ceylon. London: Hurst and Blackett.

48. Lynch, C. (2007). Juki Girls, Good Girls: Gender and Cultural Politics in Sri Lanka's Global Garment Industry. Ithaca, N.Y.: Cornell University Press.

49. Magliozzi, D., Saperstein, A. and Westbrook, L. (2016). Scaling up: Representing gender diversity in survey research. Socius. 2: 1-11.

50. Mani, L. (1998). Contentious traditions: The debate on sati in colonial India. Berkeley: University of California Press.

51. Messerschmidt, J., Connell, R., Messner, M., and Martin, P. eds. (2018). Gender reckonings: New social theory and research. NYU Press.

52. Miller, J. and K. Carbon-Lopez (2013). Gendered Carceral Regimes in Sri Lanka: Colonial Laws, Postcolonial Practices, and the Social Control of Sex Workers. Signs 39 (1), 79-103.

53. Mohanty, C. (2003). Feminism without borders: Decolonizing theory, practicing solidarity. Durham: Duke University Press.

54. Nagel, J. (1998). Masculinity and nationalism: gender and sexuality in the making of nations. Ethnic and racial studies. 21(2): 242-269.

55. Nayak, S. (2014). The Raj agent in Ceylon 1936-1940. New Delhi: Education Resources Center Trust. 
56. Obeyesekere, G. (1970). Religious symbolism and political change in Ceylon. Modern Ceylon studies. 1(1): 43-63.

57. Percival, R. (1803). An account of the Island of Ceylon: Containing its history, geography, natural history with the manners and customs. London: Baldwin.

58. Powell, Christopher, and François Dépelteau, (eds). (2013). Conceptualizing relational sociology: Ontological and theoretical issues. Springer.

59. Riley, N. (2005). Demography of gender. In Handbook of population, pp. 109-141. Springer, US.

60. Risman, B. (2017). 2016 Southern Sociological Society presidential address: Are millennials cracking the gender structure? Social currents. 4(3): 208-227.

61. Risseeuw, C. (1988). The fish don't talk about the water: Gender transformation, power and resistance among women in Sri Lanka. Leiden: E.J. Brill.

62. Ruwanpura (2013). Scripted Performances? Local Readings of "Global” Health and Safety Standards (The Apparel Sector in Sri Lanka), Global Labour Journal 4(2):88-108.

63. Schatz, E., and Williams, J. (2012). Measuring gender and reproductive health in Africa using demographic and health surveys: the need for mixed-methods research. Culture, health \& sexuality. 14(7), 811-826.

64. Sirr, H.C. (1850). Ceylon and the Cingalese. London: William Shoberl.

65. Spivak, G. (1988). Can the subaltern speak? In C. Nelson \& L. Grossberg (eds.), Marxism and the interpretation of culture, 271-313. Urbana Champaign: University of Illinois Press. 66. Stacey, J, and Thorne, B. (1985). The missing feminist revolution in sociology. Social problems. 32(4): 301-316.

67. Zacharias, U. (2001). Trial by fire: Gender, power and citizenship in narratives of the 
nation. Social text. 19 (4): 29-51. 